\title{
Retroperitoneal fibrosis: retrospective descriptive study on clinical features and management
}

\author{
This article was published in the following Dove Press journal: \\ Research and Reports in Urology \\ 26 October 2016 \\ Number of times this article has been viewed
}

\author{
Ann-Sophie Laroche' \\ Robert Z Bell' \\ Sarah Bezzaoucha' \\ Eva Földes ${ }^{2}$ \\ Caroline Lamarche' \\ Michel Vallée' \\ 'Section of Nephrology, ${ }^{2}$ Section of \\ Internal Medicine, Department of \\ Medicine, Maisonneuve-Rosemont \\ Hospital, University of Montreal, \\ Montreal, QC, Canada
}

Introduction: Retroperitoneal fibrosis (RPF) is a rare condition characterized by the presence of inflammatory and fibrous retroperitoneal tissue that often encases the ureters or abdominal organs. This study describes the clinical characteristics, diagnostic methods, and treatments and their effects on renal function.

Methods: We conducted a retrospective analysis of patients diagnosed with RPF at Maisonneuve-Rosemont Hospital.

Results: We identified 17 patients with RPF between 1998 and 2013. Eight patients were females $(47 \%)$, and the mean age was $62 \pm 18$ years. Eleven patients were idiopathic. Back pain was the most common symptom. All diagnoses were made based on the finding of a retroperitoneal mass on the computed tomography scan. Three patients had histological diagnosis of RPF and seven patients had unspecific changes on their biopsy. Twelve patients needed double-J stents, three patients had a temporary percutaneous nephrostomy, two patients had to have a nephrectomy for refractory ureteral obstruction, and one patient required hemodialysis. Ten patients with idiopathic RPF received medical treatment. In the treated group, only two patients had complete remission of the disease and five patients had improvement of their lesions. There were no deteriorations and only one relapse. Seven patients did not receive any treatment; two of them achieved complete remission, one of them deteriorated, and two of them had no changes. Conclusion: Most of our cases of RPF were idiopathic. Almost all treated patients received prednisone and seemed to respond, at least partially. There was a lot of heterogeneity in patient management, which makes it difficult to compare treatment effects. However, treated patients seemed to have more favorable outcomes than those who were not.

Keywords: retroperitoneal fibrosis, hydronephrosis, renal failure

\section{Introduction}

Retroperitoneal fibrosis (RPF) is a chronic inflammatory disease characterized by progressive entrapment of ureters and vessels in the retroperitoneum leading to ureteral obstruction and renal failure. More than two-thirds of the cases are idiopathic. ${ }^{1,2}$ However, many conditions have been described as the cause of RPF, such as vasoactive medication, radiotherapy, amyloïdosis, infections, Erdheim-Chester disease, many autoimmune disorders, and cancers - particularly abdominal lymphomas and carcinoid tumors. ${ }^{1-3}$

While the physiopathology of idiopathic RPF remains unclear, there are two leading theories: 1) It could reflect exaggerated local reaction to aortic atherosclerosis, supported by the finding of activated T- and B-lymphocytes in the aortic walls. ${ }^{1,2}$ However, atherosclerotic disease is not always present in many cases. Some investigators believe
Correspondence: Michel Vallée Section of Nephrology, Department of Medicine, Maisonneuve-Rosemont Hospital, University of Montreal, 54I5 Boulevard de l'Assomption, Montreal, QC HIT 2M4, Canada

$\mathrm{Tel}+\mathrm{I} 5 \mathrm{I} 2523400$ ext3489

Fax + I $5 \mid 42553026$

Email mvallee.hmr@ssss.gouv.qc.ca 
that RPF is a manifestation of a systemic autoimmune disease, supported by high levels of acute-phase reactants and autoantibodies found in the disease. ${ }^{1-4} 2$ ) It is also recognized that RPF can be a clinical feature in immunoglobulin G4 (IgG4)-related disease characterized by infiltration of lymphoplasmacytic cells in the involved organs. ${ }^{5-7}$

Diagnosis can be difficult to make, because RPF frequently presents with unspecific symptoms, such as fatigue, back pain, anorexia, weight loss, and with or without urinary symptoms. ${ }^{1,2,8,9}$ Most of the time, it is found in the setting of acute renal failure investigations. A computed tomography (CT) scan or magnetic resonance imaging (MRI) usually reveals a retroperitoneal mass with entrapment of ureter and surrounding organs. ${ }^{10-13}$ Hydroureters and hydronephrosis are frequent. Histopathologic findings are often nonspecific but reflect chronic inflammation and occasionally feature vasculitic findings. ${ }^{1,2,9,14}$

A surgical approach is usually preferred to address local complications when there is a severe urinary obstruction with renal failure. Various urologic interventions can be used to alleviate urinary obstruction and restore kidney function, but ureteral stent placement and ureterolysis are preferred. ${ }^{1,2,8,14,15}$ An interesting study showed that some patients underwent ureterolysis, intraperitonealization, and ureteral protection with PTFE vascular prosthetics. This technique uses polytetrafluoroethylene prosthetics to protect the ureter from extrinsic compression caused by RPF with good results. ${ }^{16}$

As for the medical treatment of idiopathic RPF, most cases seem to respond to immunosuppressive drugs. Most clinicians use oral corticosteroids to control inflammation, but repeated courses of treatment are often necessary, due to frequent relapse..$^{1,2,14,17,18}$ In a randomized trial, prednisone was demonstrated to be superior to tamoxifen for maintenance therapy for the prevention of relapses, after induction treatment with prednisone, in patients with idiopathic RPF. Therefore, prednisone should be considered in patients with RPF. ${ }^{17}$ There are no other randomized trials comparing the different therapeutic options, but many case reports support the use of azathioprine, methotrexate, mycophenolate mofetil, tamoxifen, and cyclophosphamide..$^{1,2,14,15,18,19}$ Several cases of spontaneous recovery are also reported..$^{5,6,14,15}$

The aim of our study was to report the clinical characteristics, diagnostic methods, treatments and their efficacy, as well as the evolution of patients with RPF at our center.

\section{Methods}

We identified patients with RPF from January 1998 to December 2013 admitted to the urology, internal medicine, and nephrology departments at Maisonneuve-Rosemont
Hospital. We searched patients' files using the International Classification of Diseases, ninth edition, codes for idiopathic RPF, hydronephrosis, and hydroureters. The diagnostic criteria were retroperitoneal soft tissue mass surrounding inferior vena cava, aorta, or ureters on contrast-enhanced CT scan. In this retrospective study, there was no formal follow-up protocol. The follow-up was in accordance with individualized usual clinical care and varied considerably. Improvement was defined as a better renal function on follow-up compared to baseline. This study was approved by the Institutional Review Board of Hôpital Maisonneuve-Rosemont who deemed patient consent not necessary as this was a retrospective study without intervention.

\section{Results}

\section{Patient characteristics}

Clinical data of 17 patients with RPF between 1998 and 2013 were collected and analyzed. Nine patients were males and eight patients were females. The mean age was $62 \pm 18$ years (ranged 29-83 years). Eleven patients had idiopathic RPF (64.7\%), four patients had RPF secondary to a neoplasia, one patient's RPF was thought to be in the setting of an IgG4-related disease, and one patient's RPF was caused by radiotherapy. Back pain was the most common symptom (Table 1). Comorbidities included hypertension (70.5\%), dyslipidemia (64.7\%), and diabetes mellitus (35.2\%). Two patients had underlying rheumatoid arthritis. Nine patients either were current smokers or had a positive smoking history. Eight patients had previously identifiable risk factor for RPF, one patient had a history of tuberculosis, eight patients had previous abdominal surgery, three patients had a history of malignant tumor (one patient had non-Hodgkin lymphoma and two patients had vesical tumor), and three patients used $\beta$-blockers. No asbestos exposure was reported.

\section{Laboratory results}

All patients had abnormal renal function at the time of diagnosis, with mean serum creatinine of $310.2 \mu \mathrm{mol} / \mathrm{L}$ (range 96.0-1330.4 $\mu \mathrm{mol} / \mathrm{L}), 70.6 \%$ of them had acute renal failure. Eleven patients $(64.7 \%)$ remained with chronic renal failure

Table I Baseline characteristics and symptoms at presentation

\begin{tabular}{ll}
\hline Characteristics & $\mathbf{n}(\%)$ \\
\hline Male & $9(52.9)$ \\
Caucasian & $1 \mathrm{I}(64.7)$ \\
Back pain & $7(41.2)$ \\
Weight loss & $4(23.5)$ \\
Lower limb edema & $5(29.4)$ \\
\hline
\end{tabular}


Table 2 Baseline and final creatinine ${ }^{\mathrm{a}}$

\begin{tabular}{|c|c|c|c|}
\hline & n (\%) & $\begin{array}{l}\text { Baseline } \\
\text { creatinine, } \\
\mu \mathrm{mol} / \mathrm{L} \text { (range) }\end{array}$ & $\begin{array}{l}\text { Final } \\
\text { creatinine }^{a}, \\
\mu \mathrm{mol} / \mathrm{L} \text { (range) }\end{array}$ \\
\hline All patients & $17(100)$ & $243.0(80-1330)$ & $132.5(62-448)$ \\
\hline Treated patients & $10(58.8)$ & $259.3(80-1330)$ & $104.6(62-169)$ \\
\hline Untreated patients & $7(4 \mid .2)$ & $219.9(88-547)$ & $188.4(103-448)^{b}$ \\
\hline
\end{tabular}

Table 3 Evolution of serum creatinine levels

\begin{tabular}{lllll}
\hline & $\mathbf{n}(\%)$ & $\begin{array}{l}\text { Improve, } \\
\mathbf{n}(\%)\end{array}$ & $\begin{array}{l}\text { Deteriorate, } \\
\mathbf{n}(\%)\end{array}$ & $\begin{array}{l}\text { No change, } \\
\mathbf{n}(\%)\end{array}$ \\
\hline All patients $^{\mathrm{a}}$ & $17(100)$ & $7(41.2)$ & $5(29.4)$ & $3(17.6)$ \\
Treated patients & $10(58.8)$ & $5(50.0)$ & $3(30.0)$ & $2(20.0)$ \\
$\begin{array}{l}\text { Untreated } \\
\text { patients }\end{array}$ & $7(41.2)$ & $2(28.6)$ & $2(28.6)$ & $1(14.3)$ \\
\hline
\end{tabular}

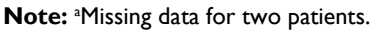

with an estimated glomerular filtration rate between $30 \mathrm{~mL} / \mathrm{min}$ and $59 \mathrm{~mL} / \mathrm{min}$. Most patients with acute renal failure seemed to improve over time (Table 2). Only a small percentage of patients had a decline in their renal function over the course of their follow-up, but most importantly, treated patients had a greater reduction in their creatinine (Table 3 ).

As for other laboratory results, seven patients $(41.2 \%)$ had anemia, with the mean hemoglobin of $117.4 \mathrm{~g} / \mathrm{L}$ (range 86-146 g/L). Erythrocyte sedimentation rate was elevated for 12 patients with a mean value of $50.6 \mathrm{~mm} / \mathrm{h}($ range $8-120 \mathrm{~mm} / \mathrm{h}$ ), but data were missing for four patients. The mean $\mathrm{C}$-reactive protein was $50.6 \mathrm{mg} / \mathrm{L}$ (range $6.7-90.4 \mathrm{mg} / \mathrm{L}$ ). $\mathrm{IgG} 4$ was measured in eight patients (47.1\%) but was elevated in only two patients (range 6.28-31.4 g/L). Antinuclear antibody was measured in seven patients and was positive in only two patients.

\section{Radiological examinations}

All patients had the retroperitoneal mass detected by contrast-enhanced CT scan. The majority of radiology reports demonstrated a perivascular tissular infiltration of the retroperitoneum and sheath surrounding the ureters. Most cases demonstrated encasement of the aorta, but there was also involvement of inferior vena cava in three patients (17.6\%). Several patients had secondary hydronephrosis and/or hydroureters. Two patients were diagnosed with inferior vena cava thrombosis caused by mass compression, and there were also two unilateral deep vein thromboses of the lower limb in our cohort. F-fluoro-deoxy-D-glucose positron emission tomography was performed in eight patients, and all revealed a hypermetabolic soft-tissue mass of the retroperitoneum (standardized uptake value $>5.5$ ), although it was not used to monitor treatment response. Ultrasound echography was per- formed initially in eight patients and demonstrated unilateral hydronephrosis in five patients and bilateral involvement in the remaining patients. Retroperitoneal mass was not visible. There was no aneurysm of the aorta in our cohort.

\section{Histological examinations}

There was no biopsy for seven patients (41.1\%), and diagnosis for those patients was made with imagery results and laboratory findings. Of the ten patients who had eleven biopsy specimens, one specimen was made by cystoscopy, two specimens was made via CT scan, and eight specimens were open biopsies. Only three specimens were histologically compatible with the diagnosis of RPF, defined as diffuse inflammatory cell infiltration with perivascular aggregates and fibrous tissue. One specimen was inconclusive, and all the other specimens had nonspecific inflammatory findings, which could also be compatible with RPF.

\section{Treatment}

The duration of the follow-up ranged from 1 month to 156 months, with a median of 26 months. Treatments included glucocorticoids alone or in combination with tamoxifen, methotrexate, and colchicine. Some patients required surgical interventions. Modalities of treatment are shown in Table 4. Ten patients $(58.8 \%)$ received medical treatment including eight patients with idiopathic RPF, one patient with IgG4related disease, and one patient with abdominal non-Hodgkin lymphoma. Ten patients received prednisone with a mean initial dose of $60 \mathrm{mg} / \mathrm{d}$ (ranging from $40-80 \mathrm{mg} / \mathrm{d}$ ), which was tapered gradually over the course of a few months. Six patients were treated with prednisone alone, and four patients received a combination of prednisone with tamoxifen, methotrexate, or colchicine. In the treated group, only two patients had complete remission of the disease. Nonetheless, six patients had an improvement of their lesions on CT scan and showed a decrease in erythrocyte sedimentation rate and C-reactive protein levels. No patients deteriorated and there was only one relapse that was successfully treated with a second course of oral prednisone. Seven patients did not receive any treatment, most of them because of the amelioration or stability of the lesion; three of them achieved complete remission, three of them had no changes, and one patient not treated deteriorated, but data were incomplete as he was lost to follow-up. Surgical interventions were needed in some patients. Twelve patients needed double-J stents, three patients had a temporary percutaneous nephrostomy, one patient had an open ureterolysis and intraperitonealization of ureters, and two patients had to have a nephrectomy. Only one patient on medical treatment has no surgical intervention. All intervention in this group of 
Table 4 Modality of treatment for the 17 patients with RPF

\begin{tabular}{|c|c|}
\hline Treatment & n (\%) \\
\hline \multicolumn{2}{|l|}{ Medical treatment } \\
\hline Prednisone alone & $6(35.3)$ \\
\hline Combination with prednisone & $4(23.5)$ \\
\hline Tamoxifen & I (5.9) \\
\hline Methotrexate & $2(11.8)$ \\
\hline Colchicine & $\mathrm{I}(5.9)$ \\
\hline No medical treatment & $7(41.2)$ \\
\hline \multicolumn{2}{|l|}{ Surgical interventions } \\
\hline Intraureteral double-J stent implantation & $12(70.6)$ \\
\hline Percutaneous nephrostomy & $3(17.6)$ \\
\hline Open ureterolysis and intraperitonealization of ureters & I (5.9) \\
\hline Nephrostomy & $2(11.8)$ \\
\hline No surgical intervention & $3(17.6)$ \\
\hline
\end{tabular}

Abbreviation: RPF, retroperitoneal fibrosis.

patients was aimed to alleviate urinary obstruction. None of the patients treated surgically had renal function deterioration during the follow-up period. Only one patient required temporary hemodialysis $(5.8 \%)$.

\section{Discussion}

RPF is a rare inflammatory disease that can lead to compression of vascular and urinary structures, causing hydronephrosis. ${ }^{1-3}$ Our study demonstrated that RPF affected patients between 29 years and 82 years of age with back pain as their chief complaint with five patients presenting lower extremity edema. Ureteral encasement with secondary hydronephrosis was observed in the majority of patients.

All our patients had some degree of acute renal failure, and $60.7 \%$ remained with some degree of renal failure once treated, which is higher than that in previous studies. ${ }^{1,2,8,9}$ However, the creatinine was still generally lower at the end of the follow-up period with $41.2 \%$ of our patients improving their renal function. This benefit seemed higher in the treated patient group, but almost all patients on medical treatment have had surgical intervention. All intervention in this group of patients was aimed to alleviate urinary obstruction: this can obviously influence clinical outcome.

Antinuclear antibody and IgG4 were seldom measured, so we cannot interpret their significance. Only one patient had RPF in an IgG4-related disease proven with biopsy.

The management and follow-up parameters were heterogeneous, probably reflecting the different approaches whether the patients were treated by an urologist, a nephrologist, or an internist. There seemed to be an association among mass activity, regression on imaging, and the decrease in acute-phase reactants. Even though acute-phase reactants lack sensitivity and specificity for the diagnosis of RPF, they could be taken into account when evaluating the treatment success, although further investigations are required.
Ultrasonography was usually performed and showed hydronephrosis, although it has poor sensitivity in detecting RPF mass. ${ }^{3,5,11,12}$ Among our cohort CT scan remained the preferred imaging method for diagnosis and follow-up of the soft-tissue density mass of the retroperitoneum. Recently, F-fluoro-deoxy-D-glucose positron emission tomography emerged as a technique of choice to evaluate active inflammation and assess treatment response, ${ }^{12,13}$ but it was not used for that purpose in our cohort of patients.

As for treatment, studies demonstrated that corticosteroids should be considered as the treatment of choice in RPF. 14,15,17-19 Many immunosuppressive strategies were described in previous studies, and agents used in our cohort seem to reflect the lack of consensus in the management of RPF.

\section{Conclusion}

We noted that most of our cases of RPF were idiopathic and were diagnosed mainly based on the pathognomonic radiologic features on CT scan. Most of the treated patients received prednisone and seemed to respond, at least partially. There was a lot of heterogeneity in patient management, which makes it difficult to compare treatment effects; however, there seems to be a positive effect of the treatments on the evolution of the renal function.

\section{Disclosure}

The authors report no conflicts of interest in this work.

\section{References}

1. Vaglio A, Salvarani C, Buzio C. Retroperitoneal fibrosis. Lancet. 2006;367(9506):241-251.

2. von Bommel EF. Retroperitoneal fibrosis. Neth J Med. 2002;60(6): 231-242.

3. Scheel PJ Jr, Feeley N. Retroperitoneal fibrosis: the clinical, laboratory, and radiographic presentation. Medicine (Baltimore). 2009;88(4): 202-207.

4. Magrey MN, Husni ME, Kushner I, Calabrese LH. Do acute-phase reactants predict response to glucocorticoid therapy in retroperitoneal fibrosis? Arthritis Rheum. 2009;61(5):674-679.

5. Hamano H, Kawa S, Ochi Y, et al. Hydronephrosis associated with retroperitoneal fibrosis and sclerosing pancreatitis. Lancet. 2002; 359(9315):1403-1404.

6. Neild GH, Rodriguez-Justo M, Wall C, Connolly JO. Hyper-IgG4 disease: report and characterisation of a new disease. BMC Med. 2006;4:23.

7. Stone JR. Aortitis, periaortitis, and retroperitoneal fibrosis, as manifestations of IgG4-related systemic disease. Curr Opin Rheumatol. 2011; 23(1):88-94.

8. An LM, Xu YF, Zhang ZL. Clinical features and prognostic analysis of retroperitoneal fibrosis in 32 patients (in Chinese). Beijing Da Xue Хие Bao. 2012;44(2):265-269.

9. Ha YJ, Jung SJ, Lee KH, Lee SW, Lee SK, Park YB. Retroperitoneal fibrosis in 27 Korean patients: single center experience. J Korean Med Sci. 2011;26(8):985-990.

10. von Bommel EF, Jansen I, Hendriksz TR, Aarnoudse AL. Idiopathic retroperitoneal fibrosis: prospective evaluation of incidence and clinicoradiologic presentation. Medicine (Baltimore). 2009;88(4):193-201. 
11. Cronin CG, Lohan DG, Blake MA, Roche C, McCarthy P, Murphy JM. Retroperitoneal fibrosis: a review of clinical features and imaging findings. AJR Am J Roentgenol. 2008;191(2):423-431.

12. Goenka AH, Shah SN, Remer EM. Imaging of the retroperitoneum. Radiol Clin North Am. 2012;50(2):333-355.

13. Moroni G, Castellani M, Balzani A, et al. The value of (18)F-FDG PET/ $\mathrm{CT}$ in the assessment of active idiopathic retroperitoneal fibrosis. Eur J Nucl Med Mol Imaging. 2012;39(10):1635-1642.

14. Swartz RD. Idiopathic retroperitoneal fibrosis: a review of the pathogenesis and approaches to treatment. Am J Kidney Dis. 2009;54(3): 546-553.

15. Cristian S, Cristian M, Cristian P, et al. Management of idiopathic retroperitoneal fibrosis from the urologist's perspective. Ther Adv Urol. 2015;7(2):85-99.
16. Conceição P, Sousa L, Azinhais P, et al. Utilização de Próteses Vasculares de PTFE para Protecção dos Ureteres na Fibrose Retroperitoneal Idiopática - A Experiência de um Serviço de Urologia [Use of Vascular Prostheses PTFE for Protection of Ureters in Retroperitoneal Fibrosis Idiopathic - The Experience of Urology Service]. Acta Urol. 2009;26(4):19-24.

17. Vaglio A, Palmisano A, Alberici F, et al. Prednisone versus tamoxifen in patients with idiopathic retroperitoneal fibrosis: an open-label randomised controlled trial. Lancet. 2011;378(9788):338-346.

18. Warnatz K, Keskin AG, Uhl M, et al. Immunosuppressive treatment of chronic periaortitis: a retrospective study of 20 patients with chronic periaortitis and a review of the literature. Ann Rheum Dis. 2005;64(6):828-833.

19. Jois RN, Kerrigan N, Scott DG. Mycophenolate mofetil for maintenance of remission in idiopathic retroperitoneal fibrosis. Rheumatology (Oxford). 2007;46(4):717-718.
Research and Reports in Urology

\section{Publish your work in this journal}

Research and Reports in Urology is an international, peer-reviewed, open access journal publishing original research, reports, editorials, reviews and commentaries on all aspects of adult and pediatric urology in the clinic and laboratory including the following topics: Pathology, pathophysiology of urological disease; Investigation and treatment of

\section{Dovepress}

urological disease; Pharmacology of drugs used for the treatment of urological disease. The manuscript management system is completely online and includes a very quick and fair peer-review system, which is all easy to use. Visit http://www.dovepress.com/testimonials.php to read real quotes from published authors. 